\title{
Age de Carvalho e Benedito Nunes: um poeta e um crítico
}

\author{
Age de Carvalho and Benedito Nunes: a poet and a critic
}

Maria de Fatima do NASCIMENTO*

Universidade Federal do Pará (UFPA)

RESUMO: O artigo examina a relação entre Benedito Nunes (1929-2011) e Age de Carvalho (1958-), respectivamente crítico e poeta paraenses. Em 1980, o poeta participa de um concurso de poesias e também o crítico avalia o certame. Age de Carvalho, um dos premiados, ganha a publicação de seu primeiro livro, Arquitetura dos ossos (1980). Constata-se então que Benedito Nunes passa a ser um leitor especializado de Age de Carvalho, cuja obra de estreia tem orelha escrita pelo crítico brasileiro. Os dois intelectuais mantêm contatos sobre arte poética e Benedito Nunes publica ainda, a respeito de Age de Carvalho, apresentações, orelhas e posfácios, como “Jogo marcado", para A fala entre parêntesis (1982), livro produzido por seu autor e outro poeta paraense, Max Martins, além de fazer em alemão, para a obra Sangue-Gesang (2006), posfácio republicado em português em Do Marajó ao arquivo: breve panorama da cultura do Pará (2012), de Benedito Nunes.

PALAVRAS-CHAVE: Age de Carvalho. Benedito Nunes. Poesia. Crítica literária

ABSTRACT: The paper examines the relationship between Benedito Nunes (1929-2011) and Age de Carvalho (1958-), who were respectively a critic and a poet from Pará. In 1980, the poet enters a contest which is judged by the critic. Age de Carvalho, one of the winners, gets his first book, Arquitetura dos ossos (1980), published. Benedito Nunes becomes an expert in Age de Carvalho. His first book has a cover review written by the Brazilian critic. Both intellectuals mantain contact and discuss about poetry. Benedito Nunes writes introductions, covers, and postscripts about Age de Carvalho's writings. One example is "Jogo marcado", written for A fala entre parêntesis (1982), a book published by Age de Carvalho and another poet from Pará, Max Martins. Another example is the postscrip for Sangue-Guesang (2006), written first in German and later, translated to Portuguese for Do Marajó ao arquivo: breve panorama da cultura do Pará (2012).

\footnotetext{
* Doutora em Teoria e História Literária pela Universidade Estadual de Campinas (UNICAMP). Professora de Literatura Brasileira da Faculdade de Letras (FALE) e da Pós-Graduação do Instituto de Letras e Comunicação (ILC) da Universidade Federal do Pará (UFPA). Pós-Doutoranda em Letras pela Universidade de São Paulo (USP). E-mail: mafana@ufpa.br
}

Enviado em 22/07/2018 e aprovado em 26/07/2018 
KEYWORDS: Age de Carvalho. Benedito Nunes. Poetry. Literary Criticism

\section{Introdução}

Age de Carvalho (1958-) nasceu em Belém (PA) e estreou na poesia, aos 22 anos, com o livro Arquitetura dos ossos, publicado em 1980, pela Falângola, Editora do Pará, livro esse premiado num concurso público ocorrido na capital do estado. Em abril do mesmo ano, por intermédio do crítico estético-literário Benedito Nunes (1929-2011), que integrou a comissão avaliadora do certame, Age de Carvalho recebeu o convite para participar de um encontro que acontecia aos sábados na casa do crítico. Lá foi apresentado a um poeta conterrâneo e igualmente premiado no mesmo concurso, mas por outro jurado, Max Martins (1926-2009), com quem fez amizade e escreveu em 1982 A fala entre parêntesis, livro constituído de um poema em forma de haicai e publicado em Belém pela SEMEC Grapho/Grafisa. Daí em diante, cresceu a amizade entre os dois poetas, que passaram a manter "[...] um diálogo por quase trinta anos, que incluiria leituras, viagens e vasta correspondência" (CARVALHO, 2015, p. 99). Esse convite do crítico ao poeta possibilitou relações literárias frutíferas para Age de Carvalho, que se tornou o grande poeta que é hoje.

No presente artigo, examinamos a crítica literária de Benedito Nunes produzida sobre Arquitetura dos ossos, obra para a qual ele fez a orelha, deixando a marca de um leitor atento e perspicaz com relação à linguagem da poesia de Age de Carvalho. Embora o crítico ainda tivesse escrito a apresentação de A fala entre parêntesis (1982), obra de Age de Carvalho em coautoria com seu mentor Max Martins, bem como um posfácio para Sangue-Gesang (2006), apreciação na qual fez um balanço, até àquele momento, da produção do autor em epígrafe, dada a extensão do trabalho ora apresentado, discutimos apenas o primeiro texto nuniano a respeito do primeiro livro de Age de Carvalho.

\section{O papel de Benedito Nunes como crítico literário em Belém e a importância de uma premiação}

A premiação do livro Arquitetura dos ossos e outras questões da vida de nosso autor lemos em Age de Carvalho: poemas (2017), livro no qual ele concedeu uma longa 
entrevista a Sérgio Cohn, Mayara Ribeiro Guimarães e André Vallias. Ali se reportou a tal período como importante para seu trabalho, tendo sido despertado para a arte verbal por uma professora que ministrava um curso de literatura aos sábados em Belém do Pará. Por meio dela, passou a ler, em antologias, grandes poetas da literatura brasileira, como Carlos Drummond de Andrade, Manuel Bandeira e especialmente Ferreira Gullar, de Luta corporal (1954), Dentro da noite veloz (1975) e Poema sujo (1976), textos de grande relevância para a escrita de seu primeiro livro. No entanto, posteriormente conquistando o mencionado prêmio decisivo para sua atual condição literária, enquanto marco de um poeta iniciante, Age de Carvalho reconheceu que foi pela convivência com Benedito Nunes e Max Martins, ouvindo e dialogando muito, que ele criou uma base sólida de leituras mais difíceis à época, a começar por Grande sertão: veredas (1956). Isso porque Age de Carvalho passou então a privar da convivência de um grupo de intelectuais que frequentava a casa de Benedito Nunes e discutia literatura, destacandose Max Martins e Benedito Nunes, num período em que nosso autor passou a ler outros poetas e romancistas, a exemplo de Guimarães Rosa. O próprio Age de Carvalho demonstra, na referida entrevista, o lugar matricial que Benedito Nunes e Max Martins ocupam na sua trajetória poética:

[...] $\mathrm{Na}$ verdade, fui integrado a esse grupo de amigos que se reunia na Travessa Estrela, onde fica a bela casa de Benedito Nunes e Maria Sylvia. Haroldo Maranhão, o romancista, outro a pertencer a essa geração brilhante, certamente a melhor que o Pará já deu, vivia no Rio de Janeiro nessa época e frequentava a casa também quando aparecia na cidade. E através dessas pessoas maravilhosas que foram Benedito Nunes e Max, fui criando uma base de leitura. Eu ouvia muito... (CARVALHO, 2017, p. 70).

A "geração brilhante", grupo a que Age de Carvalho se reportou, denominamos “Geração Moderna do Pará de 1946" em nossa tese de doutorado, Benedito Nunes e a moderna crítica literária Brasileira (1946-1969), v. I, de 2012, geração essa constituída de muitos poetas, entre eles, quatro amigos, Benedito Nunes, Haroldo Maranhão, Max Martins e Mário Faustino, que estiveram juntos quase cinco anos, lendo, discutindo e escrevendo poemas, crítica literária sobre prosas e versos, além de terem lido textos filosóficos e publicado de 5 de maio de 1946 a 14 de janeiro de 1951, no "Suplemento Arte Literatura", orientado por Haroldo Maranhão, neto do dono do jornal Folha do Norte. 
Foram os quatro amigos que sobressaíram no cenário local e nacional após o encerramento da publicação do referido periódico. Porém, o grupo era bem maior, já que o Suplemento congregou três gerações de poetas e outros literatos, incluindo o crítico literário Francisco Paulo Mendes, os poetas Ruy Barata e Paulo Plinio Abreu, tradutor de uma obra de Rainer Maria Rilke, Elegias de Duíno (1923), os quais vinham de uma segunda geração, e ainda Bruno de Menezes, da primeira geração do Modernismo no Pará.

Contudo, dos quatro amigos, que na época foram chamados em jornal de "Novíssimos" por Peri Augusto, apenas dois de início são reconhecidos nacionalmente, por uma crítica especializada, como grandes literatos. Isso porque os dois foram logo estudados e inseridos nas principais Histórias Literárias Brasileiras do século XX e tiveram leitores de universidades brasileiras, a exemplo de Benedito Nunes, ainda na década de 1960, assim que ele publicou $O$ dorso do tigre, livro inserido nos cursos de Letras do Centro-Sul por professores como Antonio Candido e Décio de Almeida Prado. Esse fato impulsionou a divulgação do nome e obra do crítico paraense.

Depois, sobre Mário Faustino, que após sua morte foi estudado e passou a figurar em vários livros, a crítica literária e os poetas reconheceram a potência de sua poesia. Não obstante, ele, que teve Benedito Nunes como seu principal estudioso e divulgador, até o momento não conseguiu chamar a atenção de um amplo leitorado. Inclusive, seu único livro, O homem e sua hora (1955), ficou esgotado há anos.

Haroldo Maranhão, último a produzir suas obras, somente a partir de 1968 cultivou o gênero conto e, a partir de 1982, o romance. Embora tenha sido agraciado com muitos prêmios, não está ainda incorporado pelas histórias literárias dos centros culturais de prestígio.

Max Martins, nosso grande poeta do período, firmou-se como um dos mais lidos em nossa terra, mas ainda não obteve o merecido reconhecimento nacional. Dos quatro amigos citados, ele foi o primeiro a publicar livro, em 1952, com o título $O$ estranho, para o qual Benedito Nunes faz o prefácio, assim como em 1992, para a produção intitulada Não para consolar, fez o texto "Max Martins: mestre aprendiz", um prefácio importante e uma espécie de matriz para quem estuda a obra desse autor, que continuou publicando poemas até a morte. 
Morto em 1962 num desastre de avião, Mário Faustino foi o segundo a publicar livro e, a partir de 1956, organizou no Rio de Janeiro, precisamente no "Suplemento Dominical" do Jornal do Brasil, as páginas da coluna "Poesia-Experiência". Antes de sua estreia em 23 de setembro de 1956, acerca de Benedito Nunes, que também publica, de 1956 até 1961, no Jornal do Brasil, diz Nascimento: “Ali, sua estreia ocorre em 5 de agosto de 1956, com o artigo "O homem e sua hora", sobre a obra homônima de Mário Faustino. Semelhante artigo tem sua continuação em 12 de agosto do mesmo ano, antes do lançamento de "Poesia-Experiência"... (NASCIMENTO, 2012, p. 90).

O terceiro a publicar livro foi Benedito Nunes, que, após dar a lume, no início dos anos de 1960, os artigos a respeito de Clarice Lispector no Suplemento Literário do jornal O Estado de São Paulo, publicou O mundo de Clarice Lispector, ensaios (1966), seu primeiro livro sobre crítica literária.

E, por fim, Haroldo Maranhão estreou como contista e cronista em 1968, no Rio de Janeiro, com A estranha xícara, livro publicado pela Saga Editora. Porém, somente em 1982 publicou seu primeiro romance, O tetraneto del-rei: suas idas e venidas, obra premiada, bem recebida pela crítica e para a qual Benedito Nunes também fez a orelha e uma "Recensão Crítica”, publicada na Revista Colóquio Letras, em Lisboa, 1984.

Observamos que alguns desses literatos foram logo reconhecidos fora do seu estado, a exemplo de Benedito Nunes e Mário Faustino. Outros o foram posteriormente, como é o caso de Haroldo Maranhão, que, a partir de 1982, passou a receber vários prêmios por seus livros, inclusive tendo seu romance A porta mágica (1983) como leitura obrigatória em escolas brasileiras de ensino básico.

Max Martins, embora sendo um grande poeta, foi pouco divulgado e a circulação de sua obra fora do estado do Pará foi bem mais recente. Verificamos que seus livros passaram a circular mais a partir de 2015, com a reedição de suas obras, sob a divulgação de Age de Carvalho, curador/organizador das edições dos livros do poeta brasileiro.

Essa retrospectiva a respeito dos quatro amigos literatos de Belém visou a esclarecer a história de convivência de Age de Carvalho com "Essa geração brilhante", que ele destacou em sua entrevista, tendo congregado em 1980 especialmente dois membros daquela geração. O primeiro foi Benedito Nunes, que na época já era professor de filosofia de uma das maiores Instituições de Ensino Superior (IES) da 
Amazônia: a Universidade Federal do Pará (UFPA), com vários livros publicados de crítica literária. O segundo foi Max Martins, também detentor de ampla produção.

Os dois amigos da década de 1940, que conviveram nos tempos do jornal Folha do Norte, mantiveram amizade em Belém do Pará e continuaram congregando com novos poetas e artistas de um modo geral, lendo, discutindo, estudando e produzindo obras importantes: um fazendo crítica literária e o outro produzindo poemas. Haroldo Maranhão, já residindo então no Rio de Janeiro, comparecia aos encontros, quando fazia visitas aos amigos de Belém.

A convivência de Age de Carvalho com os dois literatos, na década de 1980, propicia a publicação de um segundo livro, o citado A fala entre parêntesis, em parceria com Max Martins, inspirado em Renga: a chain of poems (1971), de Octavio Paz, Jacques Roubaud, Edoardo Sanguineti e Charles Tomlinson. Esse livro Benedito Nunes trouxe de Austin, Texas, Estados Unidos da América (EUA), com a intenção de traduzir, mas não chegou a fazê-lo. Em particular, no tocante à obra $A$ fala entre parêntesis, devemos ressaltar que ela possui uma história de leitura envolvendo pessoas criativas, que amam a literatura, tais como: Benedito Nunes, Maria Sylvia Nunes, Age de Carvalho e Max Martins. A aludida história foi contada por Age de Carvalho na Entrevista de 2015, aqui discutida, bem como por Benedito Nunes, que também escreveu em várias ocasiões a respeito do livro dos dois poetas paraenses (NUNES, 2012, p. 320).

Pertinentemente, mencionemos um fato interessante: o livro A fala entre parêntesis foi lançado no Rio de Janeiro na livraria Xaman, de Aloísio Leite, quando os dois poetas participaram da Oficina literária Afrânio Coutinho, lendo o poema do livro publicado: "Fomos e fizemos uma leitura da renga lá" (CARVALHO, 2017, 83-84). Em consequência dessas atividades realizadas no Rio de Janeiro, Max Martins foi inserido em A Literatura no Brasil, de Afrânio Coutinho, clássico bibliográfico dos cursos de Letras no Brasil.

No entanto, Nascimento percebeu, na referida organização de Coutinho, edição de 1999, que o estudioso Assis Brasil, um dos colaboradores da monumental obra, escreveu de forma incorreta sobre Max Martins, ou seja, sem maiores conhecimentos das obras do poeta paraense e da cultura de seu estado de origem, conforme constatamos a seguir: "Max Martins está no Maranhão escrevendo a sua boa poesia. 
Mantendo-se na área verbal, a sua poesia não é mais o intrincado metafórico, mas uma saída para novas e criativas imagens linguísticas. Publicou, em 1982, A fala entre parêntesis" (COUTINHO, 1999, p. 268, apud NASCIMENTO, 2012, p. 177). Inclusive, Assis Brasil não fez nenhuma referência à participação de Age de Carvalho na elaboração do livro.

Na década de 1980, a convite do publicitário Rosenildo Franco, convite esse extensivo a Max Martins, Age de Carvalho tomou parte num empreendimento importante para ele e para o leitorado, especialmente o de Belém, qual seja, a publicação de uma coluna de poesia no suplemento cultural "Grápho", do jornal $A$ Província do Pará. O autor de Arquitetura dos ossos, também arquiteto e design gráfico, informou que esse trabalho foi um dos mais importantes para ele, enquanto artista verbal. Conforme palavras suas: "Essa página, para o meu desenvolvimento, para a minha compreensão de poesia, foi determinante" (CARVALHO, 2017, p. 74).

Mesmo tendo aceitado o convite de Rosenildo Franco, Max Martins depois desistiu do empreendimento e Age de Carvalho sozinho realizou a produção e execução da coluna, com tradução de poemas de vários autores estrangeiros, a exemplo de Georg Trakl, Paul Celan e Rainer Kunze, ao tempo em que divulgava a poesia brasileira, como a de Carlos Drummond de Andrade, Mário Faustino e João Cabral de Melo Neto nas páginas de um caderno jornalístico tão importante para o público de Belém (CARVALHO, 2017, p. 71-72-73).

A pesquisadora Mayara Ribeiro Guimarães, professora de Literatura Brasileira da UFPA e estudiosa da obra de Age de Carvalho, publicou um relevante trabalho para a compreensão do período em que nosso poeta realizou tal atividade na imprensa paraense. Parte dessa pesquisa a estudiosa publicou no ano de $2018 \mathrm{em}$ Age de Carvalho: todavida, todavia: poesia, jornalismo e design gráfico desde 1980, em parceria com o nosso poeta, livro lançado na Feira Pan-Amazônica do Livro, de Belém do Pará, quando Age de Carvalho foi o escritor homenageado desse reconhecido evento da Capital Paraense e da Região Norte. É no sétimo capítulo do livro, "A página de poesia Grápho", que Mayara Guimarães destacou a edição desse periódico para o crescimento estético do poeta:

Dessa forma, a Grápho permitiu-lhe escolher seus lugares de diálogo, experimentar o mundo e a técnica dos poetas ali incluídos, colocando à 
disposição de novos leitores todo um repertório moderno e pessoal. Na dupla função de poeta-tradutor, conheceu os mecanismos que regem os projetos criativos de seus autores eleitos e pode desenvolver o seu próprio projeto pessoal de criação poética (GUIMARÃES, 2018, p. 219).

Ainda na década de 1980, Age de Carvalho publicou seu terceiro livro de poesias, Arena, Areia (1986). Nesse momento, ele já gozava de prestígio de uma crítica local, nomeadamente, junto a Benedito Nunes, já reconhecido nacionalmente, e a Francisco Paulo Mendes, respeitado em meio à intelectualidade local, Professor de Literatura de Belém e mentor da geração de Benedito Nunes, conforme esse último reconheceu, ao ser entrevistado em 2000, por Marcos Nobre e José Márcio Rego. Quando interrogado sobre suas leituras, afirmou: "Muitos [autores] eu descobri sozinho, como Unamuno, por exemplo. Landsbergue e Sartre foi Mendes quem descobriu. Ele era o catalisador, dava informação e julgava os poetas... (NUNES, 2000, p. 74). Foi justamente Francisco Paulo Mendes quem fez a orelha do terceiro livro de Age de Carvalho.

Na década de 1990, nosso poeta continuou produzindo, a exemplo da obra Ror (1980-1990), contendo uma seção intitulada Pedra-Um com poemas inéditos, que muitos estudiosos nomeiam como se fosse outro livro publicado. Nessa década, Age de Carvalho publicou fora de Belém do Pará, pela Coleção Claro Enigma, Editora Duas Cidades, de São Paulo. Assim, sua produção passou a circular por outros espaços, passando a ser lida em outros estados brasileiros.

Ainda na década de 1990, Age de Carvalho escreveu Móbiles (1998), em parceria com Augusto Massi, Professor de Literatura Brasileira da Universidade de São Paulo (USP) e crítico literário, que escreveu no jornal $O$ Estado de São Paulo e, na mesma década, editou obras de vários poetas brasileiros, dentre os quais citamos José Paulo Paes e Alcides Vilaça. Assinalamos essa publicação para demonstrar que Age de Carvalho, naquele período, já estava dialogando com literatos de outros estados brasileiros e fazendo parcerias. Semelhante fato veio demonstrar ser importante a circulação de obras para maior conhecimento da produção de seus autores.

Em 2003, Age de Carvalho publicou o livro Caveira 41 pelas Editoras Cosac \& Naify, de São Paulo e 7Letras, do Rio de Janeiro, estampando no mesmo ano, pela Paka-Tatu, Editora do Pará, a antologia Seleta, com poemas dos livros Arquitetura dos ossos, Arena, Areia, Ror: (1980-1990), além de poemas selecionados da seção Pedra- 
um do livro Ror (1980-1990). Em 2006, deu a lume Sangue-Gesang, pela editora Kato Kunst \& Verlag, de Berlin, com poemas de Caveira 41 e seleção de poemas de Pedra$U m$, para o qual Benedito Nunes fez um posfácio.

Age de Carvalho, em 2011, publicou o livro Trans, pela Cosac \& Naify, de São Paulo, e 7 Letras, do Rio de Janeiro. Verificamos que as publicações de seus livros a partir da década de 1990 foram saindo por Editoras qualificadas dos centros culturais de maior circulação de livros, como o eixo São Paulo-Rio. O livro Trans foi oferecido a Angelika e a Max Martins. No oferecimento para o poeta paraense, escreveu o seguinte: “A Max Martins, meu Mestre", revelando a importância do poeta amigo, cujo nome, a seus leitores pessoais, desejava divulgar.

Em 2015, Age de Carvalho trouxe a público Ainda: em viagem: poesia, pela EDUFPA, com sessenta e cinco poemas. Nesse livro, deparamos com um poema intitulado "Benedito" (p.69), remetendo, diante da morte e colocação das cinzas de seu amigo no jardim da casa, ao carinho da convivência com o crítico estético-literário do Pará: "De volta à Estrela,/exportado em cinza/deposta/sob a roseira,// de-vez. Ia de retorno, vaso.//E/ aí aonde ia,/na passagem,/ nesses recessos de agora/ só-ser em flor,/res-/ser num pé/de planta, aconteceu:/deu-se um deus,/fenômeno, sinal, consolo/talvez - //ele ali,/a roseira em-flor" (CARVALHO, 2015, P. 69). Esse poema foi republicado na seleta de poemas feita por Age de Carvalho em 2017 (p.58) e em 2018 (p.43).

Nosso poeta, em 2017, publicou a coletânea Age de Carvalho: poemas, pela Coleção Postal, Azougue Editorial/Editora Cozinha Experimental do Rio de Janeiro, com composições em versos já publicadas em Ror (1980-1990) (1990), sendo quatro poemas da seção de Pedra-Um; doze de Caveira 41 (2003); doze de Trans (2011); e quinze de Ainda em viagem (2015). Alguns desses poemas já haviam sido estampados em outras seletas, especialmente os poemas do Ror: (1980-1990), da seção Pedra-Um.

O último livro do literato enfocado, organizado por ele e por Mayara Ribeiro Guimarães, com o título de Age de Carvalho: todavida, todavia: poesia, jornalismo e design gráfico desde 1980, livro esse muito rico em informações sobre a vida, a produção poética e tradutória do autor, trouxe os principais textos críticos sobre suas obras e ainda entrevistas, depoimento, testemunho, cartas, fotografias de Age de Carvalho e uma seleção de poemas de Arquitetura dos ossos, Arena, Areia, Ror: (1980- 
1990), Caveira 41, Trans e Ainda: em viagem: poesia, bem como uma seção intitulada "Poemas inéditos" (2016-18), em que há uma demonstração por parte do autor do seu exercício de escrita de seus poemas, que foram refundidos até a versão final para publicação.

Nesse exercício, tivemos uma demonstração da necessidade, por parte de um poeta, de muitas vezes precisar escrever e reescrever suas composições, procurando, selecionando e organizando as palavras certas, com vista a expressar seus extratos emocionais mais profundos, para o que nunca nada foi gratuito, num trabalho com a linguagem próprio daquele com percepção do mundo diferente do não poeta.

O mesmo exercício de Age de Carvalho nos trouxe à memória o poema "Procura de poesia", de Carlos Drummond de Andrade: "Chega mais perto e contempla as palavras./Cada uma tem mil faces secretas sob a face neutra/e te pergunta sem interesse pela resposta/pobre ou terrível, que lhe deres:/Trouxeste a chave?”. Isso porque para o poema da página 48 do último livro de Age de Carvalho, contamos três versões datadas, conforme os dois versos que seguem como exemplo: "Segues a tua estrela,/embaixo," a primeira versão manuscrita é do dia $1^{\circ}$ de novembro de 2016; no dia 6 de novembro de 2016, o poeta elaborou a segunda versão datilografada com o título em letras de forma, com cortes de palavras e acréscimos de outras no mesmo poema; SEGUES A TUA ESTRELA,/embaixo," no mesmo dia 6 de novembro de 2016, houve outra elaboração, ou seja, a terceira versão datilografada: "SEGUES A TUA ESTRELA,/embaixo,/alémnuvens, o fulgurante mergulho/no céu interior [...]" permanecendo o mesmo título, porém com cortes e acréscimos de palavras no corpo do poema, como se essa terceira versão fosse a que o poeta publicaria em livro, mas ainda com mudanças de palavras. Dessa forma, verificamos no livro em foco outros poemas escritos dessa maneira, em que percebemos a importância do exercício poético.

\section{Benedito Nunes: leitor e crítico da obra de Age de Carvalho}

O exercício poético, que Age de Carvalho desenvolveu e publicou em seu livro de 2018, foi uma das práticas dos quatro amigos da "Geração Moderna do Pará de 1946', quais sejam, Benedito Nunes, Haroldo Maranhão, Max Martins e Mário Faustino. Eles pensavam que o autor de poesia, romance ou crítica literária devia ler 
com assiduidade as obras literárias e pensar na inovação da linguagem para seus textos. Porém, devido aos limites do artigo, destacamos aqui apenas Benedito Nunes, que optou pela crítica literária e foi um dos maiores estudiosos do romance, da poesia e da filosofia no Brasil, surgindo nessa geração da década de 1940 em Belém do Pará.

Benedito Nunes nos informou que, no início de sua carreira como Professor de Filosofia, lia muito e fazia várias traduções de livros de filosofia ou de poemas para ministrar suas aulas, o que o ajudou a fazer sua crítica. Vejamos um trecho de entrevista concedida em 2000:

Lia Hegel durante meses, toda a Fenomenologia do espírito, a Filosofia da história, etc. e ia anotando num caderno. Passava em seguida para Husserl, lia As ideias para uma filosofia fenomenológica. [...]. Li sistematicamente também Heidegger. Primeiro Li em espanhol, que foi a primeira tradução de Heidegger, anterior à tradução francesa. A tradução francesa foi tardia, como também a brasileira (NENES, 2000, p. 70).

Constatamos estudos de Benedito Nunes desde as primeiras críticas que fez a seus colegas Haroldo Maranhão, Mário Faustino, Max Martins, Ruy Barata e a ele próprio, entre outros que publicavam poesia no encarte literário surgido em 1946. Era um grande leitor, sempre atento às questões de linguagem dos poemas que lia. Como observou Nascimento, a partir de uma análise feita por Benedito Nunes em 1950 e intitulada "Dez poetas paraenses", o crítico brasileiro foi um dos primeiros estudiosos dessa geração em causa aqui no Pará:

\begin{abstract}
As principais questões tratadas por Nunes no citado artigo sobre tais poetas dizem respeito ao uso inadequado da linguagem, do "material poético" empregado por eles, falta de "vivências poéticas", falta de técnica, a artificialidade da linguagem e das imagens, o uso ainda entre esses poetas da forma parnasiana, bem como informações sobre a natureza da poesia e do poeta. O crítico ensina que um bom poema passa por "um processo contínuo de trocas entre a realidade objetiva e a subjetividade", de modo que haja "uma fusão orgânica de duas realidades", em que o produto final se torne "simbólico". Afirmando que somente assim "o poeta cria um mundo que é seu, cuja base ontológica é a palavra que fundiu dois mundos aparentemente incompatíveis" (NASCIMENTO, 2012, p. 143).
\end{abstract}

Quando houve o encerramento do "Suplemento Arte Literatura" do jornal Folha do Norte, em 14 de janeiro de 1951, em Belém do Pará, Benedito Nunes já era reconhecido pelos seus pares como crítico literário. Tanto foi que em 1952 ele fez o prefácio do livro $O$ estranho, de Max Martins e depois no mesmo ano escreveu um longo artigo na Folha do Norte sobre o livro do amigo intitulado "A estreia de um poeta”. Porém, em jornais fora de Belém, Benedito Nunes publicou a partir de 1956, 
primeiro no Jornal do Brasil do Rio de Janeiro e posteriormente no O Estado de São Paulo. Lido por grandes intelectuais, começou a ser convidado para publicação de livros. Assim, deu a lume $O$ dorso do tigre (1969), divisor de águas na carreira do crítico literário paraense, que fez juízo de valor de diversos literatos do país e de sua terra natal.

Benedito Nunes sustentou uma crítica de seus conterrâneos desde 1950 até à morte, participando como membro de concurso literário, fazendo orelhas e apresentações, publicando ensaios em jornais e livros, recensões críticas em revistas para todos eles. Proferindo conferências, palestras; participando de mesas-redondas em congressos, dando entrevistas a convite de Universidades do Brasil e do estrangeiro.

Assim foi que Benedito Nunes integrou a equipe avaliadora do concurso de poemas em que Age de Carvalho ganhou prêmio, fazendo a orelha de Arquitetura dos ossos (1980). O texto de Benedito Nunes de um único parágrafo trouxe um auspicioso destino para nosso poeta, que veio a demonstrar em sua produção aquilo que Benedito Nunes teorizou sobre sua poesia inicial. Perspicaz que era, enquanto leitor de poesia, desde o início de sua carreira, o crítico paraense pensou a linguagem poética como “não-instrumental”, conforme seu texto que deu início à fortuna crítica da obra de Age de Carvalho, continuando válido na atualidade:

A poesia é o modo não-instrumental de lidar com a linguagem. Se as
palavras, desviadas do consumo imediato a que o intercâmbio da
comunicação corrente as expõe, passam a falar por si mesmas para além de
seus significados comuns; se organizadas em padrões rítmicos também
dizem das coisas pela pulsação do sentimento que os anima, deixando em
cada verso ou frase uma significação em suspenso, como pergunta e
perplexidade ou uma significação tensa, como agressão e protesto; se
finalmente desencadeiam, entre som e sentido, o "poder de silêncio", que
concentram, como apelo capaz de revelar o mundo ao homem e o homem a si
mesmo - então quem emprega a palavra desse modo não- instrumental se faz
poeta, porque cria da linguagem um espaço intersubjetivo de conhecimento e
de encontro dialogal; Essa conduta lúdica para com a linguagem, lida e
luta, que identifica o genuíno poeta, identificando-o à sua obra, marca os
poemas de Age de carvalho em Arquitetura dos osso (NUNES, 1980).

Destacamos com "grifos nossos" as orações subordinativas condicionais empregadas por Benedito Nunes, em seu texto da orelha do livro de Age de Carvalho Arquitetura dos ossos. Ali se faziam presentes as teorias que o guiavam para fazer seus julgamentos, demonstrando o estudioso que era, a partir da leitura dos poemas de um escritor iniciante, chegando a seguinte conclusão: os poemas do livro apreciado 
atendiam as essas teorias. Portanto, Age de Carvalho era um "Poeta", no sentido original e mais profundo da palavra, qual seja, um criador verbal.

Esse vaticínio de Benedito Nunes carregou-se de uma simbologia muito importante para um poeta iniciante. Comprovamos que Benedito Nunes, enquanto crítico, assumia posições muito sólidas, em decorrência de leituras que fez desde criança, aperfeiçoando-se nessa arte, na qual deixou-nos primorosos textos matriciais, como esse aparentemente pequeno de extensão, mas poderoso em seu significado.

\section{Considerações finais}

A orelha do livro Arquitetura dos ossos, de Age de Carvalho, foi apenas uma das questões que tentamos esclarecer para o leitor a respeito do crítico literário brasileiro e de sua relação literária com nosso poeta. Todavia, ao fazer o artigo que ora concluímos, lemos muitos livros e repensamos outros lidos. De onde querermos registrar aquilo que estamos pensando sobre a leitura, circulação e divulgação de obras literárias (poesia, romance e crítica), num local como Belém do Pará, longe do Centro-Sul do Brasil, onde sempre existiu uma maior circulação de obras, haja vista os investimentos governamentais por longas décadas e uma maior oportunidade para artistas da área de linguagem. Noutras palavras, reconhecemos a importância de sermos bons escritores como condição primordial para o mundo das letras. Contudo, é preciso que tenhamos bons leitores para nossas obras, divulgando nossas produções, do contrário não saímos do limbo.

Em todas as épocas, se fez necessária essa corrente, o reconhecimento dos pares, dos críticos literários, das instituições letradas, especialmente das Universidades, como aconteceu com Age de Carvalho, que foi lido por Benedito Nunes, um dos maiores críticos do Brasil da segunda metade do século XX, e deve ter sido recomendado para outros estudiosos. Percebemos que, quando Benedito Nunes, avaliava uma obra, ela passava a ser vista como algo precioso.

Vimos que todos os escritores paraenses, com projeção nacional de suas obras, foram aqueles que fizeram parcerias e se relacionaram com colegas locais, nacionais e até internacionais; com críticos e docentes que se interessaram por suas obras, lendo-as e divulgando-as. Foi assim com Benedito Nunes, Mário Faustino, Haroldo Maranhão e 
Max Martins, continuando com Age de Carvalho, que teve grandes leitores entre aqueles adolescentes que iniciaram suas produções na década de 1940, tornaram-se grandes leitores literários e o acolheram na década de 1980.

\section{REFERÊNCIAS:}

CARVALHO, Age. Arquitetura dos ossos: poesia. Belém: Falângola, 1980. Arena, areia. Belém: Editora Grafisa/Edições Grapho, 1986. A fala entre parêntesis. Belém: Edições Grapha/SEMEC, 1982. Ror: 1980-1990 - Poesias Reunidas. São Paulo. Duas cidades, 1990. Móbiles. Rio de Janeiro: 7Letras, 1998. Caveira 41. São Paulo: Cosac \& Naify; Rio de Janeiro: 7Letras, 2003. Seleta, Age de Carvalho. Belém: Paka-Tatu, 2003. Sangue-Gesang. Berlin: Kato Kunst \& Verlag, 2006. Trans. São Paulo: Cosac \& Naify; Rio de Janeiro: 7 Letras, 2011. Ainda em viagem. Poesia. Belém. Ed. UFPA, 2015.

Age de Carvalho: Poemas. Rio de Janeiro: Coleção Postal, Azougue Editorial/ Editora Cozinha Experimental, 2017.

Age de Carvalho: Todavida, Todavia. Organização Age de Carvalho e Mayara Ribeiro Guimarães. Belém: SECULT-PA, 2018.

A cadela. Arquitetura dos ossos. Orelhas apresentações. In. Do Marajó ao arquivo: breve panorama da cultura do Pará. Victor Sales Pinheiro (Org.). Belém: SECULT, 2012, p.370-371.

Epitalâmio. Caveira 41. Orelhas/apresentações. In. Do Marajó ao arquivo: breve panorama da cultura do Pará. Victor Sales Pinheiro (Org.). Belém: SECULT, 2012, p. 371-372.

COUTINHO, Afrânio (Direção). A literatura no Brasil, v. 6. São Paulo: Global 1999, p. 268.

GUIMARÃES. Mayara Ribeiro. Age de Carvalho: poeta da Exlândia. In. Age de Carvalho: Poemas. Rio de Janeiro: Coleção Postal, Azougue Editorial/ Editora Cozinha Experimental, 2017, p. 96-104.

O perfume da Letra Solitária. In. Todavida, Todavia. Organização Age de Carvalho e Mayara Ribeiro Guimarães. Belém: SECULT-PA, 2018, p. 164-174 
Age de Carvalho: Todavida, Todavia. Organização Age de Carvalho e Mayara Ribeiro Guimarães. Belém: SECULT-PA, 2018.

MARTINS, Max \& CARVALHO, Age de. A fala entre parêntesis. Belém: Edições Grapha, SEMEC, 1982.

NASCIMENTO, Maria de Fatima do. Benedito Nunes e a moderna crítica literária Brasileira (1946-1969), v. I, 2012, 343 p. Tese (Doutorado em Teoria e História Literária) - Instituto de Ensino da Linguagem (IEL), Universidade Estadual de Campinas (UNICAMP), São Paulo, 2012.

Benedito Nunes e a moderna crítica literária Brasileira (1946-1969), v. II, Anexos/Acervos, 2012, 579 p. Tese (Doutorado em Teoria e História Literária) Instituto de Ensino da Linguagem (IEL), Universidade Estadual de Campinas (UNICAMP), São Paulo, 2012.

NOBRE, Marcos. REGO, José Marcio. Conversa com filósofos brasileiros. São Paulo: Ed. 34, 2000.

NUNES, Benedito. (João Afonso: pseudônimo de Benedito Nunes). Dez poetas paraenses. Folha do Norte. Belém, 31 dez. 1950, Suplemento Arte Letras, p. 4-2.

Orelha-Apresentação. In. Arquitetura dos Ossos: poesia. CARVELHO, Age de. Belém: Falângola, 1980.

Jogo Marcado. Orelha-prefácio. In. A fala entre parêntesis. MARTINS, Max \& CARVALHO, Age. Belém: Edições Grapha, SEMEC, 1982.

Dieses Negative Wissen. [Este saber negativo]. Orelha-prefácio. In. SangueGesang. CARVALHO, Age de. Berlin: Kato Kunst \& Verlag, 2006.

Orelhas e apresentações. Jogo Marcado. In. Do Marajó ao arquivo: breve panorama da cultura do Pará. PINHEIRO, Victor Sales (Org.). Belém: SECULT, 2012, p. 320-323. 
Orelhas e apresentações. Arquitetura dos ossos. In. Do Marajó ao arquivo: breve panorama da cultura do Pará. PINHEIRO, Victor Sales (Org.). Belém: SECULT, 2012, p. 324.

Orelhas e apresentações. Sangue-Gesang. In. Do Marajó ao arquivo: breve panorama da cultura do Pará. PINHEIRO, Victor Sales (Org.). Belém: SECULT, 2012, p. 325-326.

Meus poemas favoritos de ontem e hoje, In. Do Marajó ao arquivo: breve panorama da cultura do Pará. PINHEIRO, Victor Sales (Org.). Belém: SECULT, 2012, p. 351-373.

Recensão crítica a $O$ tetraneto del-rei, de Haroldo Maranhão. In. Revista Colóquio Letras. Notas e comentários, nº 77, jan. 1984, p. 106-107. 